\title{
Enhancing the impact of LIS Research Projects
}

\section{RiLIES Project Report}

October 2011

Peter Cruickshank, Hazel Hall, Ella Taylor-Smith

Centre for Social Informatics, Edinburgh Napier University, Edinburgh EH10 5DT

Commissioned by the Research Information Network and the Library and Information Science Research Coalition

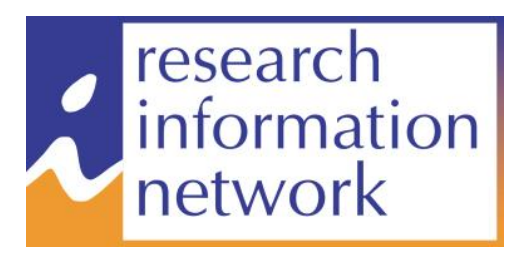

\section{Library and Information Science Research Coalition} Research Facilitating a co-ordinated and strategic approach to LIS research across the UK 


\section{Acknowledgements}

The authors acknowledge the support of the Board of Directors of the Library and Information Science (LIS) Research Coalition, and in particular its chairman, Dr Michael Jubb. Stephanie Kenna of the LIS Research Coalition also lent much appreciated support throughout the duration of the project, and at the London focus group.

Jenny Gebel, our intern from the FrauenComputerZentrumBerlin ${ }^{1}$, provided invaluable assistance in organising the focus groups and helping with the data analysis.

Sarah Morton of the Centre for Research on Families and Relationships (CRFR) at University of Edinburgh gave us important context for understanding the nature of impact in the social sciences.

We greatly appreciate the commitment made by those who took part in the case study interview process: John Vincent and Dave Muddiman (Open to all); Pete Dalton (eValued); Sheila Cannel (Researchers' use of academic libraries); Alison Brettle (Evaluating clinical librarian services); Sue Shaper and David Streatfield (School libraries in the $U K)$.

We also thank all those who took part in the focus groups, and especially the people who helped organise them: Elaine Fulton and Rhona Arthur (SLAINTE); Amanda Poulton (UC\&R) and Alison Brettle and Maria Grant (EBPLIP).

Finally, we would like to thank everyone who contributed data to the initial poll and the validation survey, and for the comments they provided to enrich our understanding of the data collected. We are also grateful to those who helped spread the word of the RiLIES project to colleagues, in particular the Professional Services and External Relations staff at CILIP.

http://fczb.de/ 


\section{Contents}

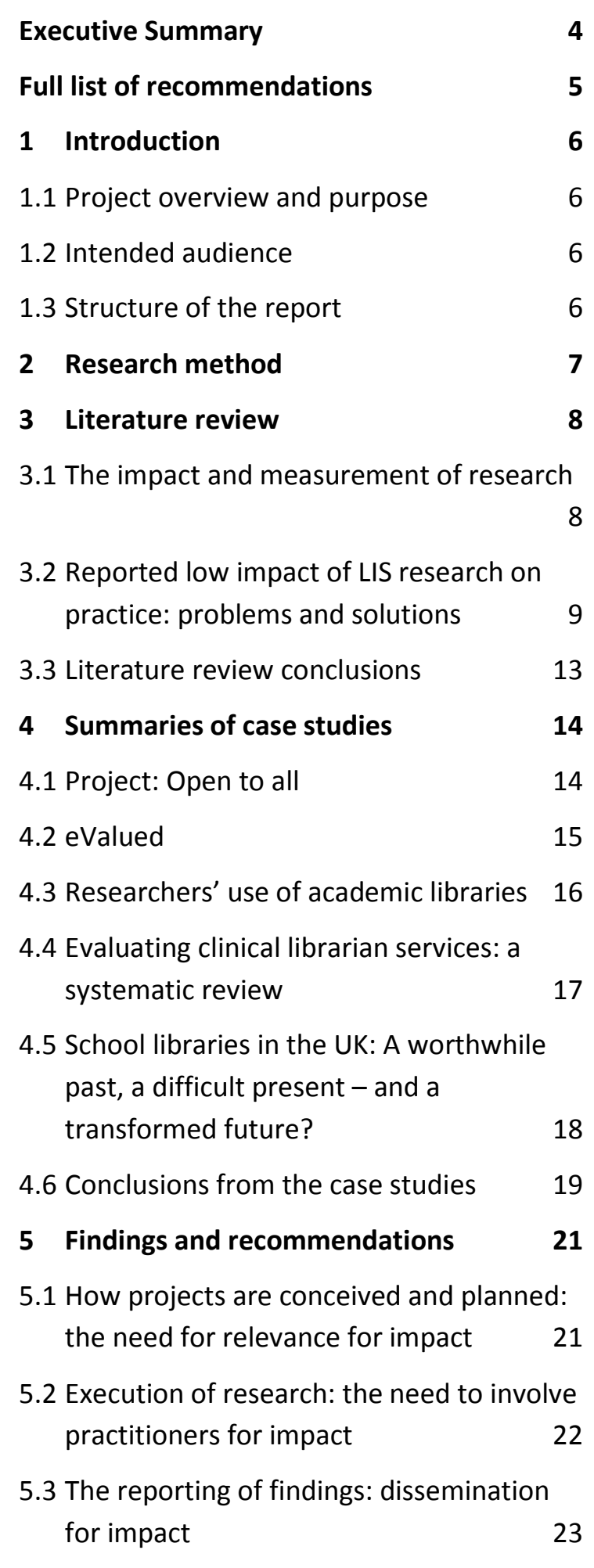

\begin{tabular}{|c|c|}
\hline \multicolumn{2}{|c|}{ 5.4 Organisational factors: Creating a } \\
\hline receptive audience & 25 \\
\hline 6 Discussion and conclusions & 26 \\
\hline 6.1 Overall conclusions & 26 \\
\hline \multicolumn{2}{|c|}{6.2 Clarifying the relationship between } \\
\hline research and practice & 26 \\
\hline Areas for further work & 1 \\
\hline Glossary and acronyms & 28 \\
\hline References & 29 \\
\hline Appendices & 31 \\
\hline
\end{tabular}

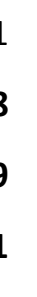




\section{Executive Summary}

The broad aim of this project was to investigate the extent to which funded research projects in the domain of library and information science (LIS) influence practice in the UK. It focused particularly on identifying factors that increase or hinder the impact of research findings on those who deliver library and information services.

The project findings derive from a review of the LIS literature on impact, a practitioner poll, case studies of five LIS research projects identified as "impactful", three sector-specific focus groups and a validation survey. The analysis of the empirical data largely confirms the findings from the literature review: that there is a disconnect between LIS research and the practitioner community; the level of impact a project enjoys depends on a number of factors, most importantly how it is planned and conceived, the extent to which practitioners are involved in its execution, and how its findings are reported. Organisational factors that support a receptive target audience for research output are also of significance to the question of impact.

The project's findings have generated new insights related to the roles of research leadership and sponsorship, and means of involving practitioners in research projects. In particular, findings

- $\quad$ highlight a preference greater than has been previously reported, for face-to-face channels for the dissemination of research results and

- reveal for the first time the role of social media in raising awareness of research.

The eleven detailed project recommendations relate to strategies to ensure that:

- $\quad$ LIS research undertaken has high level support;

- the execution of LIS research involves practitioners;

- dissemination plans for LIS research take into account practitioner preferences for consuming research output;

- LIS research output is accessible to the target audience;
- $\quad$ practitioners are given support to engage with research by their employers and professional bodies, drawing on good practice within the broad community of librarians and information scientists.

The full set of recommendations can be found on the next page. 


\section{Full list of recommendations}

How projects are conceived and planned: the need for relevance

R1. The LIS research community should develop and promote strategies that will help and encourage researchers to seek active engagement from practitioners in designing and carrying out their research.

R2. The LIS research community should develop and promote sector-specific strategies to encourage funders to support research that is relevant to the needs of the practitioner community.

R3. LIS researchers should be encouraged to seek high-profile sponsorship and ongoing support of research projects. For example, through establishing steering committees including (influential) stakeholders.

Execution of research: the need to involve practitioners

R4. LIS researchers should be encouraged to address practitioner engagement at the project planning stage, for example, by adopting methods, approaches and dissemination strategies that involve practitioners throughout the project.

Reporting findings: dissemination

R5. Researchers should be encouraged to develop dissemination strategies aligned to where and how practitioners access new information and create (embed) outputs which support the use of research results

R6. Where appropriate, researchers should be encouraged to include provision for teaching and community support materials in project plans.

R7. Researchers should be encouraged to publish reports with clear lists of recommendations, in accessible language. This is in addition to any academic papers researchers may choose to publish.

R8. Those with responsibility for freely-available open access repositories of LIS research materials should be encouraged to raise awareness of their resources amongst the practitioner communities. Similarly CILIP should publicise membership benefits that include access to a number of research publications.

Organisational factors: creating a receptive audience:

R9. The LIS research community should explore ways in which practitioners in sectors that are more receptive to research may share good practice with others.

R10. The LIS research community should consider providing training to support practitioners' interest in research.

R11. CILIP should require ongoing CPD to encourage practitioners to engage with research. 


\section{Introduction}

\subsection{Project overview and}

\section{purpose}

The RiLIES (Research in Librarianship - Impact

Evaluation) project derives from discussions at the Board of the Library and Information Science (LIS) Research Coalition, and subsequent discussions between Dr Hazel Hall, the Executive Secretary of the Coalition (from the Centre for Social Informatics at Edinburgh Napier University) and Dr Michael Jubb, the Chair of the Board of the Coalition (from the Research Information Network, RIN).

RiLIES is concerned with research impact. This has always been important, but is now rising further up the agenda of a range of constituencies, with governments across the world increasingly concerned to see evidence of socio-economic impact arising as a result of their investment in research. The "impact agenda" of the UK Research Councils and the Higher Education Funding Council for England (HEFCE) is an example of this. Additionally, in an environment where money is tight, research funders are expected to focus on projects that demonstrate value for money. In the context of public service provision, for example, it is anticipated that research projects should actively contribute to building an evidence base to support decision-making.

Previous studies indicate that the impact of LIS research projects on practice is, in general, low. It is also clear that some projects have a greater impact than others. This report offers new insights into the question of impact by studying the features of five specific research projects recognised as "impactful" combined with an investigation of how practitioners in library and information services delivery have been accessing, absorbing and using research.

The broad aim of this research project is to address the question:

To what extent does the output of funded LIS research projects influence practice of library and information services delivery in the UK?
Associated with this is the question:

What factors increase or hinder the impact of LIS research projects on practice in the UK?

The investigation was conducted between February and July 2011, in the UK.

\subsection{Intended audience}

Stakeholders who will benefit from the study include:

- Librarians and information scientists

- LIS researchers and their professional bodies, e.g. BAILER

- Bodies that fund research in the domain of LIS, e.g. AHRC, JISC

- Professional bodies, e.g. CILIP and its special interest groups such as LIRG, and consortia e.g. SCONUL, RLUK

- Employers such as local authorities, health authorities and higher education institutions (particularly with reference to training)

- $\quad$ Service end users, in the long-term, provided that the study leads to effective change.

\subsection{Structure of the report}

The body of the report starts with an overview of the research method used. The literature review identifies the factors that are possible determinants of research impact and integrates questions about these factors into the rest of the study. The project's findings are then summarised with implications and key recommendations. The conclusions include proposed areas for further research.

It should be noted that this is a summary report for the RiLIES project. A more detailed report and associated supporting material can be made available on request. 


\section{Research method}

Our empirical work was framed by a literature review (Section 3 below). This identified factors that affect the impact of LIS research. These relate to (1) how projects are conceived and planned, (2) the involvement of practitioners in the execution of research, (3) how findings are reported, and (4) factors that support the target practitioner audience to be receptive to research.

Our findings derive from data from a range of practitioners, the majority of whom work in the delivery of library and information services.

An initial poll confirmed the scope of the project and provided a broad overview of respondent practitioner perspectives of LIS research.

Three sector-specific focus groups were then held with librarians working in the public, healthcare and academic sectors (Section 4 below). These allowed for in-depth discussions of the relationships between research output, access to research, and impact on practice.

A final validation survey gave practitioners further opportunity to contribute their views of the research-practice relationship. 213 respondents completed the survey.

\begin{tabular}{|l|c|c|c|c|c|}
\hline $\begin{array}{c}\text { Respond-Front- } \\
\text { ent Role } \\
\text { / Library } \\
\text { Sector }\end{array}$ & $\begin{array}{c}\text { Manage } \\
\text { rial }\end{array}$ & $\begin{array}{c}\text { Re- } \\
\text { search }\end{array}$ & $\begin{array}{c}\text { Other/ } \\
\text { NA }\end{array}$ & $\begin{array}{c}\text { Grand } \\
\text { Total }\end{array}$ \\
\hline Academic & 30 & 28 & 10 & 12 & $\mathbf{8 0}$ \\
\hline Public & 20 & 27 & 4 & 6 & $\mathbf{5 7}$ \\
\hline $\begin{array}{l}\text { Health } \\
\text { (care) }\end{array}$ & 17 & 16 & 3 & 4 & $\mathbf{4 0}$ \\
\hline Others & 17 & 8 & 3 & 8 & $\mathbf{3 6}$ \\
\hline \hline Total & $\mathbf{8 4}$ & $\mathbf{7 9}$ & $\mathbf{2 0}$ & $\mathbf{3 0}$ & $\mathbf{2 1 3}$ \\
\hline
\end{tabular}

Table 1 Summary of responses to final validation survey

As well as collecting data from the practitioner population, we conducted case study research centred on five research projects identified from the initial poll as "impactful": (1) Open to all; (2) eValued; (3) Researchers' use of academic libraries; (4) Evaluating clinical librarian services; (5) School libraries in the UK. The case studies provided insight into the experiences of researchers involved in each project. They allowed us to identify elements of research practice that raise the possibility of a project enjoying impact amongst the practitioner community. We also traced the uptake of the results from each project in the literature. These "citation sketches" gave an indication of the academic impact of projects examined. The results of the case studies influenced the design of the focus groups outlined above, and they identified research activity that should be supported in the future.

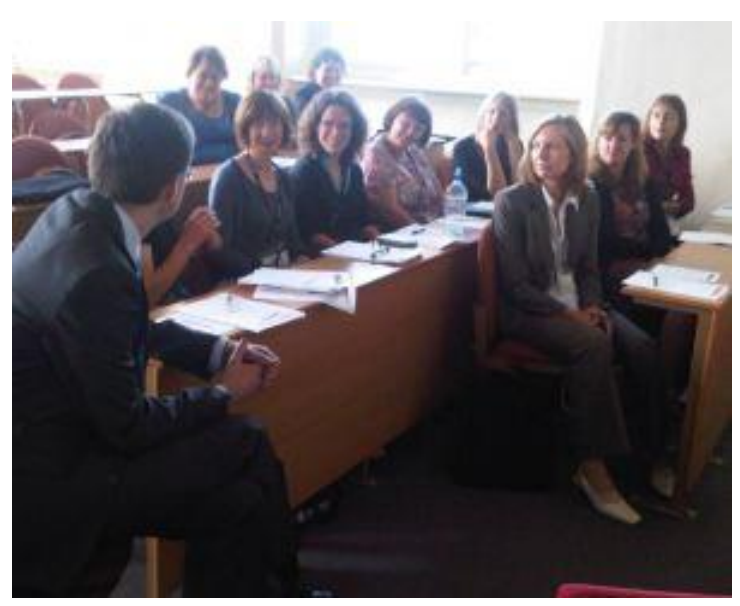

Figure 1 Discussions at the RiLIES focus group in Salford 


\section{Literature review}

\subsection{The impact and \\ measurement of research}

The impact of research and its measurement is an important research topic, particularly at a time when value for money in public spending is paramount, and the forthcoming UK assessment of academic research (REF2014) requires the submission of impact evidence for research by universities (Higher Education Funding Council for England, 2011). Proposals for REF2014 have fuelled much debate as to what might class as impact. For example, it might be argued that the straightforward use of one person's research output by another as a citation ${ }^{2}$ does not count, even where the earlier work inspires the development of further research. The main focus of the work discussed here, however, is the impact of funded research projects on a specific area of practice: library and information services provision.

Tying the output of a research project to practice in an attempt to measure its impact is not straightforward. Reasons for this are varied. For example, research from an unexpected domain often has a bearing on the practice in another (Feather, 2009, p. 179); practitioners are generally unaware that new learning such as that gained from attending a training event may be based on mediated research findings (Eve \& Schenk, 2006a, p. 12; Haddow \& Klobas, 2004, p. 39). Equally some research endeavour in LIS does not focus on immediate applicability, yet may have far reaching consequences, such as work on the history of the book which has led to the development of new resources and access to other knowledge (Feather, 2009, p. 176)

In spite of such difficulties, LIS researchers have regularly turned their attention to impact and impact measurement. Such publications can be classified into four broad categories:

\footnotetext{
${ }^{2}$ Labelled as "academic" impact in this report
}

- Work on the evaluation of library and information services. Such work may cover the impact of services on activities related to library and information services provision only, or may extend to include any wider general impact on the user population of the library or information service. The papers reviewed by Brettle, Maden-Jenkins, Anderson, McNally, Pratchett and Tancock (2011, pp. 7-10) provide examples of this category of work on impact in LIS. There is also the larger cross-sector evaluation report prepared for Re:source in 2002 (Wavell, Baxter, Johnson, \& Williams, 2002).

- Work that discusses methods for evaluating the impact of library and information services delivery, i.e. how to measure the impact of library and information services. Examples include Fried, Kochanowicz, \& Chiranov (2010); Imholz \& Arns (2007); Lockyer \& Conyers (2007); Markless \& Streatfield (2005); McNicol (2005); Melo \& Pires (2008); Poll \& Payne (2006); Rooney-Browne (2011), Town (2006); Weightman, Urquhart, Spink, \& Thomas (2009).

- Work in the domain of bibliometrics, i.e. "the quantitative study of publication collections" (Ahlgren \& Järvelin, 2010, p. 1424) by individuals, schools, universities, other types of organisation and whole nations to assess their academic impact (as defined above). See, for example Ahlgren \& Järvelin (2010); Cronin \& Meho (2007); Drummond \& Wartho (2009); Oppenheim (2007); Zhao (2010).

- Work that examines the impact of library and information science research on the practitioner work in the domain (and, to a lesser extent, how practice generates theoretical insight). Examples include Haddow (2010); Martyn \& Cronin (1983); Craghill \& Wilson (1987); Eve \& Schenk (2006b).

The research discussed in this report is concerned with the last of these four areas, taking into consideration calls for library and information services to be developed on the basis of sound research evidence (for example, Haddow \& Klobas, 2004, p. 40; McKnight \& Booth, 2010, p. 26; 
Partridge, Thorpe, \& Edwards, 2007, p. 2; Special Libraries Association, 2001; Turner, 2002, p. 230).

The ideal is that

"Research and practice, at least in theory, [should] enjoy a mutually beneficial relationship. Research should inform practice and contribute to the development of theory. Practice should benefit from research findings (particularly where those findings go towards improving the product or service provided by practitioners) and raise more questions for research" (Haddow \& Klobas, 2004, pp. 29-30).

This is important both to current local service priorities (in the context of the broader environment, as well as the local) and to the future of the broader library and information services profession (McMenemy, 2010, pp. 321-322). These priorities are also relevant to other professions (Smith \& Harvey, 2006, p. 613). Calls such as this often go unheeded. This is not an issue unique to LIS: it has also been identified in other professions, such as teaching, social work, nursing, and management (Booth, 2003, p. 3; Haddow \& Klobas, 2004, pp. 29-30; Pfeffer \& Sutton, 2006). In the case of LIS, it is not that practitioners routinely ignore other sources when planning services delivery. Rather they use sources other than published LIS research. These may include output from beyond the domain of LIS, often in the belief that it is of higher status (Weller \& Haider, 2007, p. 478). Alternatively, less formal means of gathering information from professional contacts is favoured, for example by putting out a question to a mailing list and then using collated responses to support decisions (Eve \& Schenk, 2006b, p. 8).

LIS publications that criticize the poor alignment between research findings and decision-making form part of a broader seam of literature on the notion of the "research-practice" gap (see, for example, Bawden, 2008, p. 420; Bowler \& Large, 2008; Klobas \& Clyde, 2010, p. 237; McMenemy, 2010; Ponti, 2007, p. 265; Sonnenwald, Lassi, Olson, Ponti, \& Axelsson, 2009, p. 194) and corresponding poor relationships between LIS researchers and practitioners (Feather, 2009, p. 173). For a period within the UK this misalignment was addressed, to some extent, in the set-up of the British Library Research and Development Department in the 1990s. However, the links between research and practice were effectively decoupled when the British Library's research function passed to the Library and Information Commission (LIC) in 1995, and following the merger of LIC with Re:source, later to become the Museums, Libraries and Archives Council (MLA) in 2000 (Eve \& Schenk, 2006b, p. 2).

\subsection{Reported low impact of LIS research on practice: problems and solutions}

A review of the available literature highlights reasons why LIS research output is not regularly consulted by library and information service practitioners, and thus fails to generate impact. Many authors offer advice on how to address this problem, focusing mainly on the priorities of:

1. Drawing up a relevant research agenda in the project initiation and planning stages.

2. Involving the practitioner community in the execution of the research.

3. Paying attention to research output and dissemination channels that are appropriate to the target audience.

4. Ensuring that the target audience is receptive to research output.

\subsubsection{Project initiation and planning for research impact: relevance and funding}

The relevance of LIS research to practice merits much attention in the literature. LIS research output is largely perceived by practitioners to be irrelevant, as identified in numerous studies (Ponti, 2007, p. 266). The main criticism is that LIS research does not address practical problems experienced in the workplace in general (Eve \& Schenk, 2006b, p. 9; Ponti, 2007, p. 266), nor specifically the delivery of new products or services (Eve \& Schenk, 2006b, p. 10). Bowler and Large (2008) note "Too often the gap between what researchers do and what practitioners and even the general population understand is miles apart, creating a paradox. Researchers develop theory for use in real world situations, but 
practitioners reject it because it seems to have no basis in reality" (p. 45). This is a major concern

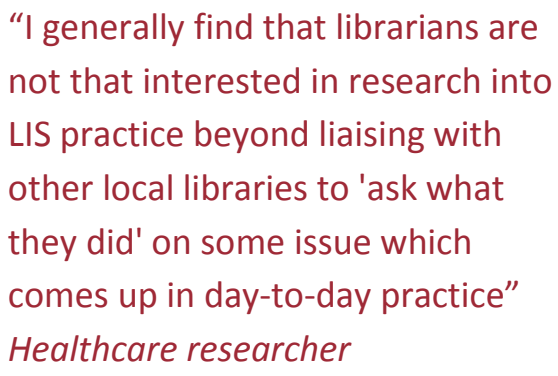

given that studies of authors (from both the researcher and the practitioner communities) have shown that they rate relevance to practice as an important consideration of the work that they publish (Klobas \& Clyde, 2010, p. 244).

Reasons for the low relevance of LIS research to practitioners include a characteristic inherent to the domain of LIS: its multidisciplinary nature (Sonnenwald, et al., 2009, p. 199). Multidisciplinarity leads to a wide variety of research output, so that just a proportion might be of interest to a particular readership. However, this does not account for the proliferation of studies that present findings relevant largely or solely to the local environment in which the research was conducted, and cannot be generalized any further (Turner, 2002, p. 232). Two other broad factors should be noted. First, LIS researchers are not sufficiently aware of the priorities and job demands of practitioners (Eve \& Schenk, 2006b, p. 4; Feather, 2009, p. 180). Second, researchers are motivated, and often driven, by frameworks for research established by grant-awarding bodies and political imperatives, which may not match the interests of practitioners (Eve \& Schenk, 2006b, p. 4; Ponti, 2007, p. 266).

Suggestions for interventions to encourage LIS researchers to work on projects to generate findings relevant to practitioner concerns include monitoring e-mail list discussions as well as seeking advice on project formulation from practitioners from the outset (Eve \& Schenk, 2006b, pp. 9-10).

It is clear that the lack of practitioner involvement in determining the direction of research has widened the gap between researchers and practitioners and resulted in a research agenda that is not shared by the two communities (McMenemy, 2010, p. 323; Ponti, 2007, p. 265). In such an environment practitioners are inhibited because they feel that they lack influence (Feather, 2009 , p. 179). It needs to be recognized by the two communities that "influence from... lay groups and everyday goals affect the selection and formulation of both the objectives of research and conceptual approaches" (Åström, 2008, p. 773). Practitioners who are currently turned off by research that lacks relevance, they will also lack interest in engaging in future research plans, which makes the problem even worse.

Some attention has been paid to another feature of project initiation and planning that may influence research impact: access to sources of funding. A bibliometric study of LIS research concludes that the academic impact of funded research is generally higher than that of research undertaken without dedicated funding (Zhao, 2010, p. 299). It is argued that may be because additional funding allows (amongst other things) investment in dissemination strategies that include attendance at high-level events that widen the reach of the work (Zhao, 2010, p. 305). As will be seen below, dissemination is a strong determining factor of research impact, so the question of how research projects are budgeted is important here.

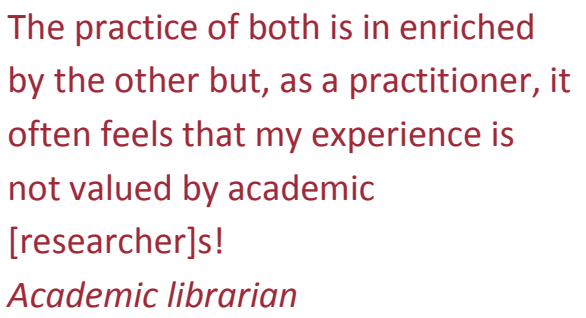

In the context of project initiation and planning for impact, it is interesting to note that the question of project sponsorship is not considered in the LIS literature. For example, the involvement of highprofile, prestigious partners may encourage interest in a piece of work, and thus raise the chances of it garnering attention and its results making an impact on practice. This is particularly interesting given that research leadership and support was identified as a major factor in an extensive ESRC-funded literature review on pathways to impact in domains other than LIS (Walter, Nutley, \& Davies, 2003, p. 30). 


\subsubsection{Execution of the research for impact: involvement of practitioners in the research}

A strong message from the literature related to how the execution of research projects relates to impact is that projects which involve practitioners are likely to have higher impact than those that do not. A study of research interests of library and information service practitioners, reported in 2004, noted that "very few librarians made use of research other than that which they had directly been involved in" (McNicol, 2004, p. 37). The level of practitioner involvement may simply be as supplier of data for a study, or it could extend to the role of research collaborator. Bowler \& Large (2008), for example, advocate a "design-based" approach in which researchers, practitioners and users are part of the research context (p. 40). They argue that design-based research results in "usable working product" which has more relevance to end-users (p. 42). Similarly, drawing on the conclusions on Haddow and Klobas (2004, p. 31), Ponti (2007, p. 267) advocates the development of "collaboratories". As well as contributing to project relevance, practitioners who are more directly involved in LIS research projects are also conduits for the dissemination of results, and this, in turn, raises impact (Eve \& Schenk, 2006b, p. 9).

What is largely missing from these messages from the literature is detail on research approaches and methods that are conducive to practitioner involvement. For example, it might be reasonable to expect some discussion of action research as a broad approach to workplace-based research. Equally, although they merit some mention, detailed descriptions of project activities such as launch events or community building for sustainability are not made available.

\subsubsection{Dissemination for impact}

In 2004 a comprehensive review of the literature on the dissemination of LIS research findings (dating back to 1975) identified poor communication of results from researchers to practitioners as a recurrent theme (Haddow \& Klobas, 2004, p. 30). This still holds true in more recent literature: two aspects of dissemination are important to research impact: (1) the nature of what is disseminated; (2) the channels that are used.

The primary complaints of relevance to the nature of what is disseminated concern difficulties with academic discourse and information overload. Each of these two factors is regularly cited in the context of a lack of practitioner time for activity related to research (for example, Berg, Hoffmann, \& Dawson, 2009, p. 593; Haddow, 2010, p. 34). With regard to academic discourse, several authors argue that practitioners believe that research output is presented in a way that is difficult to understand (for example, Eve \& Schenk, 2006b, p. 12; Haddow, 2010, p. 34; Ponti, 2007, p. 266). This may be due to unfamiliarity with specialist terminology used in textual reports of research studies (Eve \& Schenk, 2006b, p. 7; Haddow, 2010, p. 33). Practitioners also prefer a clear presentation of the implications of what is reported (Haddow, 2010, p. 34), as well as recommendations for practice made explicit in the text (Turner, 2002, p. 238). These are not always provided by the authors of research papers.

Research in the past decade has identified an appetite for research summaries aimed directly at practitioners as a means of overcoming information overload. These could accompany articles in research publications (Haddow, 2010, p. 40). Alternatively, they could be made accessible in a single place, for example on a listerv (Turner, 2002 , p. 238) or within the pages of a journal that practitioners consult on a regular basis (Haddow \& Klobas, 2004, p. 39). Similarly Eve \& Schenk (2006b, p. 13) recommended the creation of a central repository or "good practice portal" for LIS research. These recommendations have been achieved in part with the publication of evidence summaries in the open access journal Evidence based library and information practice ${ }^{3}$ (established in 2006), and the availability of other resources such as those provided by the Library and Information Research Group ${ }^{4}$ of CILIP (LIRG),

\footnotetext{
${ }^{3}$ ejournals.library.ualberta.ca/index.php/EBLIP

${ }^{4}$ www.cilip.org.uk/get-involved/special-interestgroups/research/pages/default.aspx
} 
and the repositories dLIST ${ }^{5}$ (established in 2002) and E-LIS ${ }^{6}$ (established in 2003).

Previous studies on the dissemination of research output argue that details relevant to practitioner audiences should be available in the sources that they routinely access (Haddow, 2010, p. 33; Haddow \& Klobas, 2004, p. 39; Ponti, 2007, p. 267). Practitioners and researchers favour different titles (Schlogl \& Stock, 2008, p. 650). "Popular journals" (as distinct from scholarly peerreviewed titles) are appropriate outlets (Haddow, 2010, p. 35), although they currently do not do a particularly good job of reporting research (Haddow, 2010). Even if a practitioner has an aptitude for reading the research literature in its most formal of formats, access is often difficult due to the high cost of subscriptions ${ }^{7}$ (Goulding \& Matthews, 2002, cited by Eve \& Schenk, 2006b, p. 6). Unfortunately, practitioner preferences for consuming research through the professional press create a tension for academics who wish to publish in top-rated journals. A solution here is for differentiated dissemination: academics are advised to write up more than one paper about the research project in question, as appropriate to the target audiences for the work (Eve \& Schenk, 2006b, p. 7; Shenton, 2008, p. 16)

These recommendations for the "translation of research" match with the cross-sectoral review of the literature of research impact cited above (Walter, et al., 2003). The presentation of tailored findings facilitates practitioner "tinkering" and allows this community to take ownership of the research (p. 29).

Face-to-face dissemination also attracts some limited attention in the literature. For example, academic research is distilled and then delivered through intermediaries such as trainers at events (Eve \& Schenk, 2006b, p. 12). Other intermediaries such as educators, consultants and action researchers (some of whom may be library and information service practitioners themselves) have

\footnotetext{
${ }^{5}$ dlist.sir.arizona.edu/arizona/handle/10150/105066

${ }^{6}$ eprints.rclis.org/

${ }^{7}$ It should be noted however, that CILIP members have access to a wide range of LIS titles through their membership subscription, as noted at www.cilip.org.uk/membership/benefits/ informed/Pages/default.aspx
}

a similar role (Haddow \& Klobas, 2004, p. 36). The enthusiasm of such individuals in selling new ideas and practices alongside the credibility of evidence presented is also identified in cross-sectoral review (Walter, et al., 2003, p. 29). Networking is regarded as a superior means of keeping up to date with services delivery developments (Turner, 2002 , p. 232) and for this reason it is concluded that academics should attend conferences aimed at practitioners (Eve \& Schenk, 2006b, p. 11), as well as lead the development of local joint dissemination events with their practitioner colleagues (Eve \& Schenk, 2006b, p. 10). Involvement in this kind of activity ensures that the material is tailored to the audience in question and - because everyone is in situ - audience members have the chance to ask questions directly of the research team. For these reasons learning at a conference may be a more satisfying experience than independent attempts to distil the main messages from texts (Eve \& Schenk, 2006b, p. 12).

There has also been a call for key UK practitioner conferences to move away from the model where the same notable speakers are invited to present time and time again, to one where a process of peer review gives opportunities for the less wellknown to present new research (McMenemy, 2010, p. 323). It is argued that this would refresh conference content and lead to greater practitioner interest in service innovations based on research findings.

While references to face-to-face dissemination of LIS research output are few in the literature, the role of social media in disseminating research is ignored in the work reviewed for this report. The apparently comprehensive list of possible outlets drawn up by (Haddow \& Klobas, 2004, p. 37) lacks any reference to social media, even though familiar services such as blogs, RSS, and some social networking services (for example, LinkedIn) were already established at the time that it was published. Similarly, interest was still nascent in depositing articles and making data available through open access until relatively recently.

\subsubsection{Creating a receptive audience}

It has been noted above that practitioners sometimes struggle with the research literature 
because of the way it is presented, and that lack of time hinders access. This is not to say that practitioners necessarily lack skills, but rather that they may lack confidence in the skills they do possess (Berg, et al., 2009, p. 593; Klobas \& Clyde, 2010, p. 244). Directed training about research in general, in combination with the adoption of active roles as practitioner-researchers, is proposed as a means of addressing this. If practitioners are involved in all stages of research, including writing it up and presenting at conferences (Turner, 2002, pp. 236-237), then they will become familiar with applying findings in practice, and build up other valuable skills such as the ability to navigate and evaluate high-level research papers. In recent years the LIS professional associations have directed more attention to the question of research training for librarians that goes beyond the taught component of degree courses. This addresses most criticisms that they "have not always openly encouraged the role of research in the profession" (Smith \& Harvey, 2006, p. 612).

Previous studies have found that engagement in research and appetite for training differs by sector and career stage (for example, Turner, 2002). Such findings indicate that training needs to be tailored to particular communities. A more difficult problem is motivating sections of a target population to engage in training for an activity that they do not see as relevant to their roles, or their professional development. Unlike other professions, there is no compulsion for practitioners in library and information services to engage in continuing professional development (CPD), whether or not it includes research engagement. The "duty of care" argument for CPD in other professions, such as medicine, does not apply to the practice of delivering library and information services (Haddow \& Klobas, 2004, p. 36). The motivation for practitioners to stay up to date with developments in their field therefore depends on individual interest rather than a requirement from a professional body or employer. Taking into account that practitioners work within a time-pressured environment where research may appear to be an irrelevant, or at best low-priority, activity that excludes them (as outlined above), motivation to follow up training opportunities related to research engagement is likely to be low.

\subsection{Literature review conclusions}

The misalignment of LIS research and its influence on practice has a long history, demonstrating that solutions to endemic problems are not easily found. The literature reviewed here highlights four important factors that present barriers to research impact in LIS: (1) perceptions of the low relevance of research amongst practitioners; (2) a lack of involvement of practitioners in research projects;

(3) the ineffective dissemination of research results; (4) a target audience that has not been supported in being receptive to research.

There are calls for further research to be completed on the links between research and practice with the goal of establishing professional practice that derives from research (for example, Haddow \& Klobas, 2004, p. 40). In particular, examination of research projects that have exhibited impact has been called for (Eve \& Schenk, 2006b, p. 11) with recommendations that assign responsibilities to researchers, practitioners and intermediaries as actors in the chain of research dissemination (Haddow \& Klobas, 2004, p. 39). It is timely that such work should be undertaken in the UK, both in terms of the recent increase in channels for research communication in the form of widely available social media, and the efforts of key players in the UK LIS communities to improve the links between research and practice through the establishment of the LIS Research Coalition. 


\section{Summaries of case studies}

This section presents an overview of the five "impactful" case studied which were used to explore impact from the perspective of researchers on specific projects: (1) Open to all; (2) eValued; (3) Researchers' use of academic libraries; (4) Evaluating clinical librarian services; (5) School libraries in the UK. Section 5 then draws out the findings from these case studies and relates them to the other empirical data gathered for the RiLIES project, viz the poll and survey responses, and the focus group discussions.

\subsection{Project: Open to all}

$U R L$ www.Imu.ac.uk/ies/dmudd/dmudd1.htm

Completed: 2000

Sector: Public

Funder and partners: Re:source: The Council for Museums, Archives and Libraries

Coordinated by: Dave Muddiman at University of Leeds

Findings from citation sketch: 27 primary papers 8 /book chapters; 30 citations with direct mentions of project.

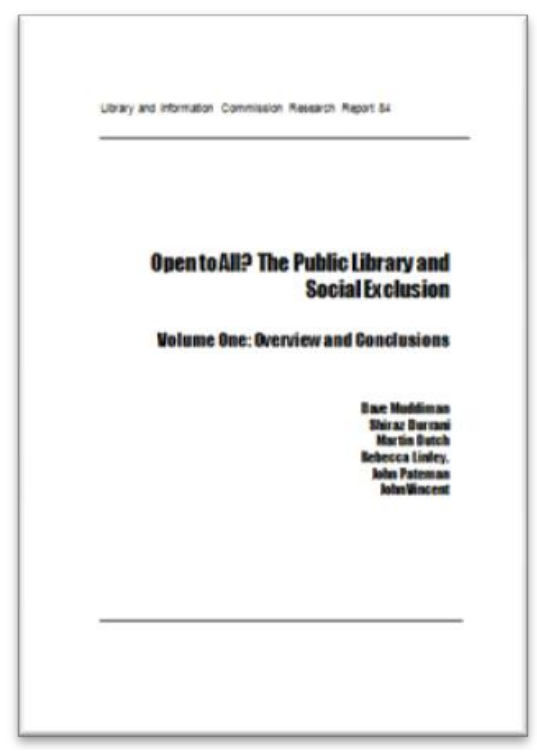

\footnotetext{
8 Primary: Written as part of project dissemination
} activity
Purpose and main findings: To investigate issues around all aspects of factors leading to exclusion by people from access to public libraries.

Findings suggested that institutional culture of the core library service needed to shift in order to become relevant to disadvantaged users. Research has an important part to play in this process, in particular as a way of identifying information and reading needs which disadvantaged people find difficult to express. A case was made for initiating a number of action research projects to develop and evaluate new modes and models.

Initiation of project and stakeholder engagement: At the time the Library and Information Commission (LIC) was working on a programme entitled Value and impact of libraries, and put out a call for research proposals. In response, the project was designed by a group of researchers who identified an opportunity to work with New Labour's social exclusion agenda.

The project did not directly follow from previous projects, but it did develop the researchers' previous work on community librarianship, equality and diversity.

A project steering board was used to bring in people who could share results with their constituencies. Dissemination routes included email lists and journal articles, as well as presentations at conferences and training courses.

Dissemination and impact: The motivation for the project was results which would lead to change, so dissemination was seen as important from the start, and commitments regarding dissemination were stated in the proposal.

Despite this, there was no explicit dissemination plan, nor were targets tracked. However, once "The Network" ${ }^{9}$ had been established in 1999, it took on a dissemination management role.

This project comprised 16 interlinked studies, each written up as a chapter in Volume 3 of the final report. This resulted in an extensive network of cross-citations that grew over the course of the work. The researchers felt that the findings of the survey and case studies (Volume 2) were under-

http://www.seapn.org.uk/ 
reported, in contrast to the policy

recommendations.

Two examples of impact of the study are:

- The "Quality Leaders" programme ${ }^{10}$, set up and supported by the MLA and Paul Hamlyn Foundation on the back of the recommendations relating to BEM (black and ethnic minorities) empowerment;

- $\quad$ The Network, which was set up for sharing good practice (using a subscription model) and is still in operation in 2011.

Lessons learned and other comments from the researchers involved in this project: The researchers acknowledged the importance of dissemination within the profession. In this case it was felt that it was a mistake not to have achieved mainstream publication of the project findings. This limited the study's legitimisation and hence its impact on the LIS establishment and policymakers at both national and local levels.

It would have been revealing to repeat the research 10 years on to see how engagement with exclusion had changed. The loss of explicit LIS research funding made it difficult to create successor projects of this nature.

Challenges that a future project in this area could address to improve its impact include:

- Achieving national level buy-in to the recommendations.

- Addressing the different requirements of each sector. For example, sometimes there is less interest from academic or business libraries in this agenda.

- $\quad$ Addressing the reluctance of library managers to send (appropriate) staff for training: that is often regarded as a less important luxury when set against other more immediate service priorities.

\section{2 eVallued}

$U R L$ www.eValued.bcu.ac.uk

Completed: 2004

Sector: Academic and general

10 http://www.seapn.org.uk/qlp/
Partners: JISC Infonet

Funders: HEFCE fund for Good Management practice

Coordinated by: Pete Dalton and others, at Birmingham City University

Findings from citation sketch: 8 primary papers; 22 citations with direct mentions of project

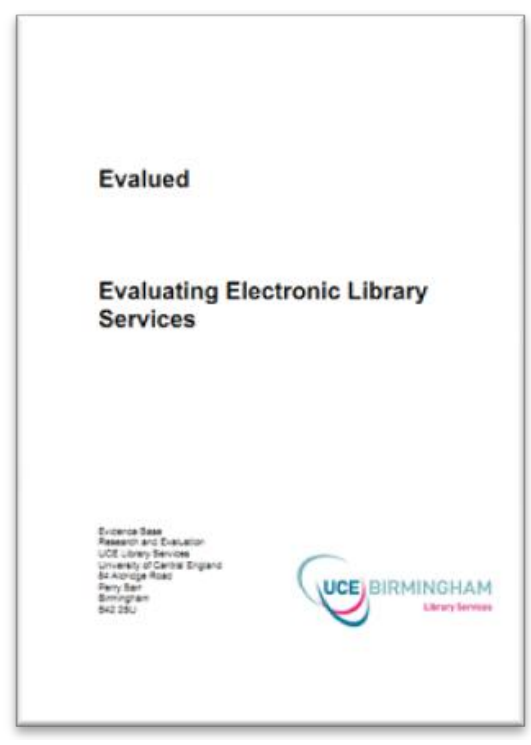

Purpose and main findings: To support library and information services staff in Higher Education Institutions (HEIs) in the evaluation of electronic information services (EIS)

The main output of this project was the development of an interactive toolkit. This emphasised qualitative methods for evaluating electronic information services, to include consideration of user experience, planning, management and impact.

Initiation of project and stakeholder engagement: The project started off as a personal idea based on evidence from undertaking evaluations and consultancy work in the sector, combined with developments in electronic information. The lead researcher, Pete Dalton, came from a digital library background and was keen to capture best practice in the area.

The project was suggested to the funder and developed iteratively, starting with an extensive literature review. The project comprised a mixture 
of research, development and engagement, with the ethos of creating a practical outcome.

Dissemination and impact: The dissemination work and training workshops served to embed the results in the community. The toolkit is still useful at a generic level. The detailed questions may have been superseded, but the toolkit is still being used for questionnaire ideas. In 2010 INASP (a training and development organisation working with overseas organisations) asked to use the toolkit as the basis of some of its training programmes. This is seen as an example of an unintended impact. The whole environment has changed since the project completed, so longer term impact is difficult to assess.

Lessons learned and other comments: Continued investment in this kind of technical resource is needed to keep it up to date. By 2011 the material needed a complete refresh. New funding could extend the useful life of the lessons learned and valuable material assembled. This highlights an issue with funding for sustainability.

A significant lesson is the importance of building up a community of practice around the project, and the provision of workshops and follow-on studies. Considerable work is needed before a community becomes self-sustaining, so there needs to be a motivation or driver for active membership. In this project, a mailing-list approach was used.

Another lesson is that the project would have benefitted from the engagement of more influential partners in its work. This would have helped roll out results. A formally organised steering group, including prestigious universities, could have made a significant difference.

\subsection{Researchers' use of}

\section{academic libraries}

$U R L$ : www.rin.ac.uk/our-work/using-and-

accessing-information-resources/researchers-useacademic-libraries-and-their-serv

Completed: 2007

Sector: Academic

Key partners: RIN, CURL, Key Perspectives Ltd
Funded by: RIN and CURL

Coordinated by: Key Perspectives (scholarly communication consultants, based in Truro).

Findings from citation review: 20 citations of the project generated from a single primary source.

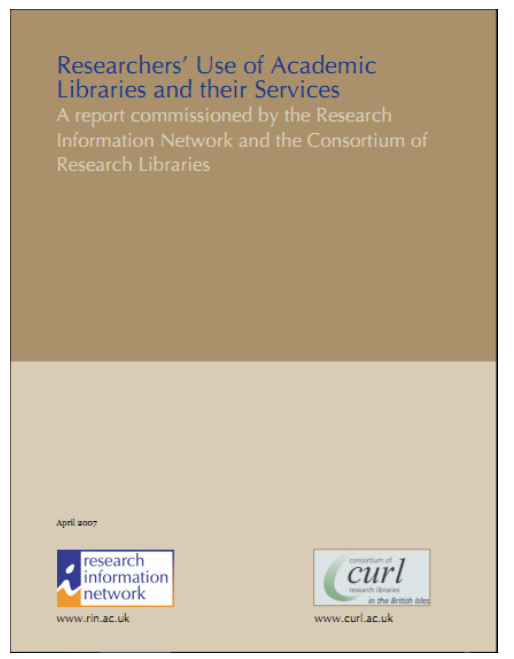

Purpose and main findings: To investigate how researchers interact with academic libraries in the UK; to inform the debate on the development of academic libraries and the services provided to researchers.

Since 2002 there had been a sharp drop in the number of science researchers who visited their institutions' library on a regular basis for help with searching print information sources. This study revealed significant differences of perception between researchers and librarians on questions related to information services delivery, for instance on the future role of libraries in supporting research.

It was concluded that communication channels needed to be improved, with the challenge of identifying the most effective way to achieve this.

Initiation of project and stakeholder engagement: The researchers were approached by RIN to take on the project. It did not arise directly from any other previous projects.

The motivation for this work was the perception that use of libraries was changing due to the impact of the Internet. The study was designed with active involvement from librarians in the $\mathrm{HE}$ sector. It was overseen by a steering group of 
librarians, and this ensured that they were strongly engaged in the project from the start.

Dissemination and impact: Direct dissemination of the project objectives and responsibilities was through the publication of the project report in booklet form. Other associated material was also produced. Access to the research outputs was supported by the membership bodies for academic libraries such as CURL and RLUK. These bodies raised awareness of the project and its results amongst librarians. There was no equivalent route for reaching researchers: they were considered too diverse a group to reach.

Other dissemination routes included a launch event, and a presentation was prepared and used in different forums, for example at a SCONUL meeting. Online, the RIN website was the main route, though some use was also made of library mailing lists.

The report was seen as part of the process of attempts to change the agenda related to academic library funding. In fact, the financial crisis encouraged academics to come out in support of research libraries.

There was a clear intention that the main audience for the research findings be decision makers at academic institutions, such as vice chancellors and deans (not least because researchers could not be reached directly). It was up to each institution to decide whether (and how) to follow up the recommendations.

Lessons learned and other comments: The team was broadly happy with process and outcome of the project, so the same approach would be used in future projects of a similar nature. There have been other subsequent RIN reports on related subjects $^{11}$, some of which include more detail on specific areas covered by this project, such as metrics or costs.

11 For instance "Reinventing research? Information practices in the humanities", available at http://www.rin.ac.uk/our-work/using-and-accessinginformation-resources/information-use-case-studieshumanities

\subsection{Evaluating clinical librarian} services: a systematic review

$U R L$ : www.nursing.salford.ac.uk/research/n\&mresearch/healthtechnologies/evaluating--librarianservices.php

Completed: 2009

Sector: Healthcare

Partners: University of Salford, North West Health Care Libraries Unit

Coordinated by: Alison Brettle

Findings from citation sketch: Two primary sources, with three additional citations.

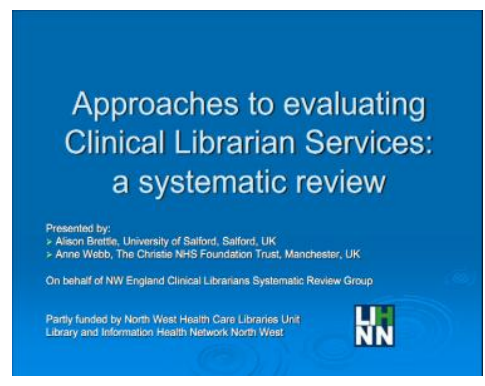

Purpose and main findings: To provide evidence on effective methods of evaluating clinical librarian services and on the effectiveness of the services; to develop associated research and critical appraisal skills and processes.

The project created practical guidance regarding the evaluation of clinical librarian (CL) services. It also updated evidence on the effectiveness and impact of CL services. The Critical Incident Technique was shown to be a useful approach to demonstrating impact, and successful in supporting the development of research and critical appraisal skills in a group of librarians.

Initiation of project and stakeholder engagement: The context against which the work was conducted is that healthcare librarians have a very strong group in the North West of England. This group provides support and motivation for constant improvement in training for the delivery of quality information services.

The lead researcher, Brettle, had presented a systematic review of information literacy in 
healthcare at the EBLIP1 ${ }^{12}$ conference. At EBLIP4, she challenged librarians to conduct more studies that would provide evidence that would support the improvement of practice. As a result the clinical librarian group contacted her with a request for help with activities such as writing for publication and conducting systematic reviews.

A bursary from the NW Healthcare Librarians group was used to teach evaluation techniques. Eight practitioners agreed to take part in the research project.

The work was seen as a capacity-building exercise which started by asking what the participants wanted to get out of the project.

Dissemination and impact: The project had an explicit dissemination strategy. This included a commitment to produce (1) a report to be spread through local networks and regional meetings and (2) an academic paper on the process.

Dissemination at conferences also formed part of this strategy.

The main audience for this study was clinical librarians, with the focus of the dissemination falling on the NW Healthcare librarians' groups. (The dissemination of results beyond the region was achieved through the production of journal articles and through attendance at conferences.) Informal conversations at conferences demonstrated that clinical librarians were particularly keen to discover whether there was any evidence of the impact or effectiveness of their services, not least because previous studies had been inconclusive.

Tutoring and mentoring was built into the project. This was intended to transfer evaluation skills and build research capacity, thereby embedding the findings in practice (in the NW region). The approach has also been adopted in the School of Nursing and Midwifery at the University of Salford. Now nursing lecturers are also benefiting from the outcomes of this study.

Lessons learned and other comments: The main lessons from this project related to balancing speed of completion and potential for long-term impact.

\footnotetext{
${ }^{12}$ Evidence Based Library and Information Practice
}

The project leaders discovered a tension between aiming for immediate effectiveness of the work and giving participants practice in decision making. Trying to ensure that all participated collaboratively slowed its operation. However, it was felt that their engagement increased project's long-term impact. Whereas tighter guidance and leadership might have resulted in faster completion, this would have been at the detriment of capacity building and hence the impact on participants.

\subsection{School libraries in the UK: A worthwhile past, a difficult present - and a transformed}

fuiture?

URL. www.cilip.org.uk/news-

media/pages/news072010.aspx

Completed: 2010

Sector: Schools

Partners: CILIP School Libraries Group (SLG)

Coordinated by: Sue Shaper and David Streatfield

Findings from citation sketch: Four primary journal articles, with a similar number of press stories. (NB this project was completed in 2010 and the publicising of its findings was still in progress in 2011.)

Purpose and main findings: A large scale survey of practitioners working in school libraries.

The main finding was evidence for the growing "gulf between the best and the rest" in school libraries.

Initiation of project and stakeholder engagement: The researchers had realised there was a need for factual information on school libraries to inform the current debate about spending. This work was partly triggered by the ending of gathering of data in this area ${ }^{13}$.

Informal contact led to the suggestion to seek funding from a bequest. It was carried out in

\footnotetext{
${ }^{13}$ Leicester University used to produce figures in this area, but the researchers had noted that a recent Parliamentary Question on numbers of school librarians showed that no figures were available.
} 
partnership with CILIP's Schools Libraries Group (SLG).

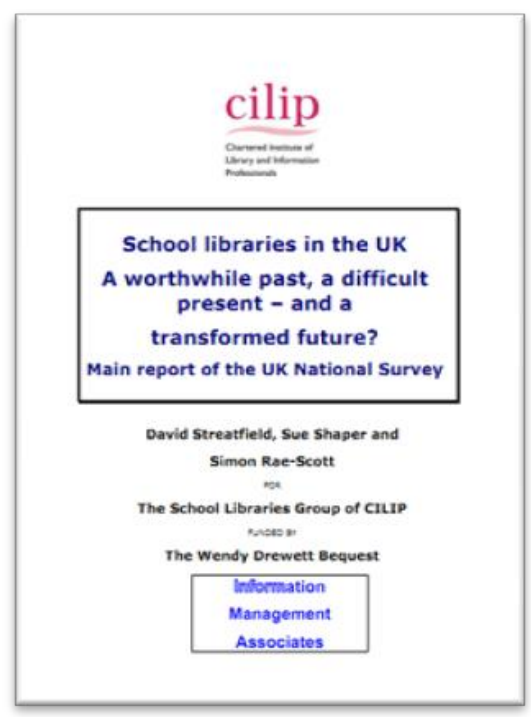

Dissemination and impact: Although there was no explicit dissemination plan or strategy, dissemination activities were well structured. The target audiences were politicians and decision makers, together with a wide range of relevant professionals and workers in librarianship, information literacy, pastoral care and literacy. The report also provided CILIP's SLG with an advocacy tool.

Because the work was commissioned by the SLG, it undertook the dissemination. An approach of staggered media releases was used. This began with a launch of key findings at a House of Commons reception, targeted at politicians and opinion formers such as senior civil servants and trades unionists. Tailored regional breakdowns of the report generated further publicity.

Additionally, articles were published and a number of conference presentations were made.

The project also provided evidence to the School Libraries Commission, chaired by the former Education Secretary Estelle Morris. Evidence given at a round table meeting was supplemented by a written submission. This made use of quotations from questionnaire responses.

Researchers involved in this project felt that the report was successful in informing and influencing the debate. For instance it contributed to policy development in Wales, and informed UNISON in the production of a policy document on the promotion of reading.

Lessons learned and other comments: In practical terms more could have been derived from the survey had more interviewees had been recruited. For example, it was known that non-qualified library staff were under-represented in the survey sample. The restricted sample set was felt to have lessened the overall impact of the research results.

Although there is uncertainty whether a follow-up study would be funded, a project at the University College of London (UCL) intends to look at the impact of school librarians.

\subsection{Conclusions from the case studies}

The five case studies share many characteristics which have contributed to their identification as "impactful" research projects. For example, in terms of their implementation, they were initiated and planned with the explicit intention of influencing practice, and they benefited from the leadership of experienced researcherpractitioners, often in close dialogue with funding bodies of the course of the projects. All demonstrate the importance of communicating with the target audience to raise the possibility for research output to inform practice, for example by running events for practitioners, as well publishing the research results. Multiple channels of communication are seen to be important, with mainstream publishing crucial for impact in the long-term. The case studies provided good examples of how to provide sustainability beyond the lifetime of the research project: Open to All created networks; eValued left a legacy of training materials and other resources. Project size did not emerge as a determinant for impact: Evaluating clinical librarian services shows that a small-scale project that is well explained can have strong influence. Funding emerges as key to the longterm impact of any project, particularly in cases where researchers would like to implement the recommendations of their 
work to date in a further study. We revisit these themes with reference to data from our practitioner poll, the focus groups and the validation survey in Section 5 below. 


\section{Findings and}

\section{recommendations}

In this section, we discuss the key findings from our research, together with our recommendations. These draw on the literature review and case studies discussed above, as well as the results of the practitioner poll, focus groups and validation survey described in Section 2.

\subsection{How projects are conceived and planned: the need for relevance for impact}

In general, practitioners perceive LIS research to be remote from their day-to-day work. This feeling is particularly evident amongst those who work in the public library sector. There is strong support amongst practitioners for LIS research projects that are driven by their needs, established in consultation with them (see Figure 2). Work that is perceived to be irrelevant is not accessed and therefore has no impact.

Practitioners are aware that researchers are motivated by frameworks for research established by grant-awarding bodies and other funders. The dialogue between funders and researchers can contribute to the possible impact of research. Feedback from practitioners suggests that this dialogue should also involve practitioners, to increase relevance. This could be achieved directly or through methods to increase researchers' and funders' awareness of practitioners' current contexts, for example by monitoring relevant email lists.
Our study indicates that, except for dissemination, the level of funding does not directly seem to influence impact; rather, effective funding causes (and supports) the establishment of a project framework and good research management practice.

Effective project leadership and support enhances impact. For instance the engagement of highprofile and prestigious individuals or organisations in a steering committee lends authority to a project. This in turn increases the chances of attracting practitioner attention and making an impact on practice. Whilst this has been discussed in the wider literature on research impact (Walter, Nutley \& Davis, 2003, p. 30), it has not been made explicit in the LIS literature before.

Our findings also show that it should not be assumed that LIS research is the only kind of research that may be of use to LIS practitioners. For example, our focus group of university librarians suggested that research into the impact

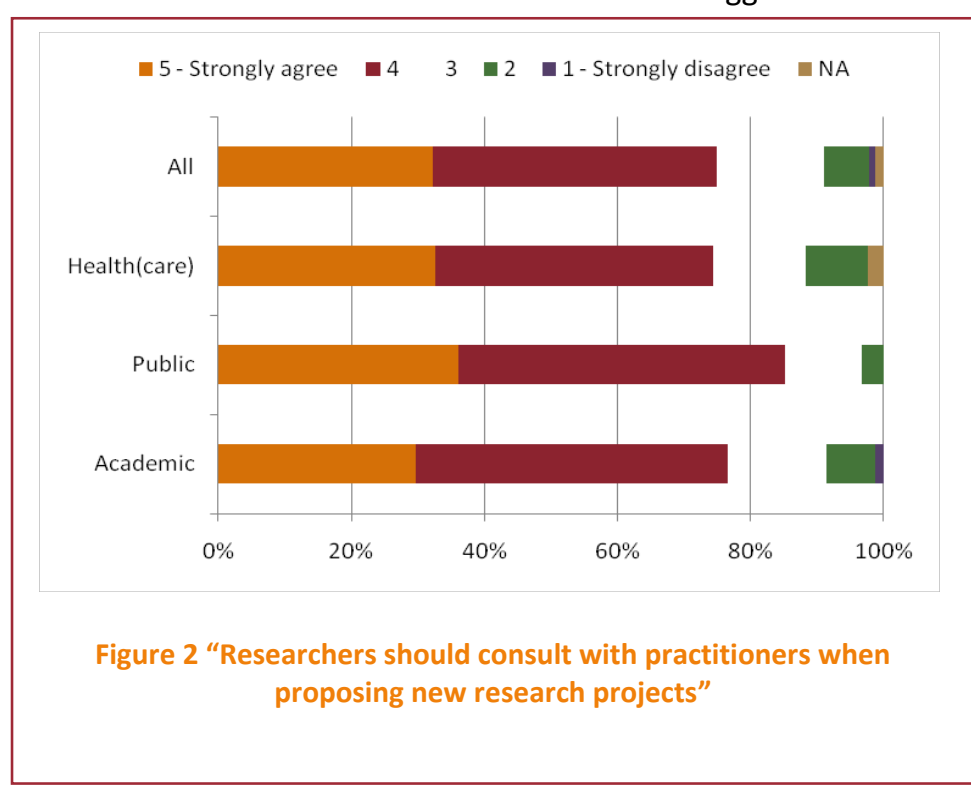
of changes in the UK Border Agency's approach to student visas would be very relevant to them. These findings are in line with previous studies about the link between LIS research and practice.

\section{Recommendations: project conception and planning for impact}

R1. The LIS research community should develop and promote strategies that will help and encourage researchers to seek active engagement from practitioners in designing and carrying out their research. 
R2. The LIS research community should develop from librarians in the HE sector, and was then and promote sector-specific strategies that will encourage funders to support research that is relevant to the needs of the practitioner community.

R3. LIS researchers should be encouraged to seek highprofile sponsorship and ongoing support

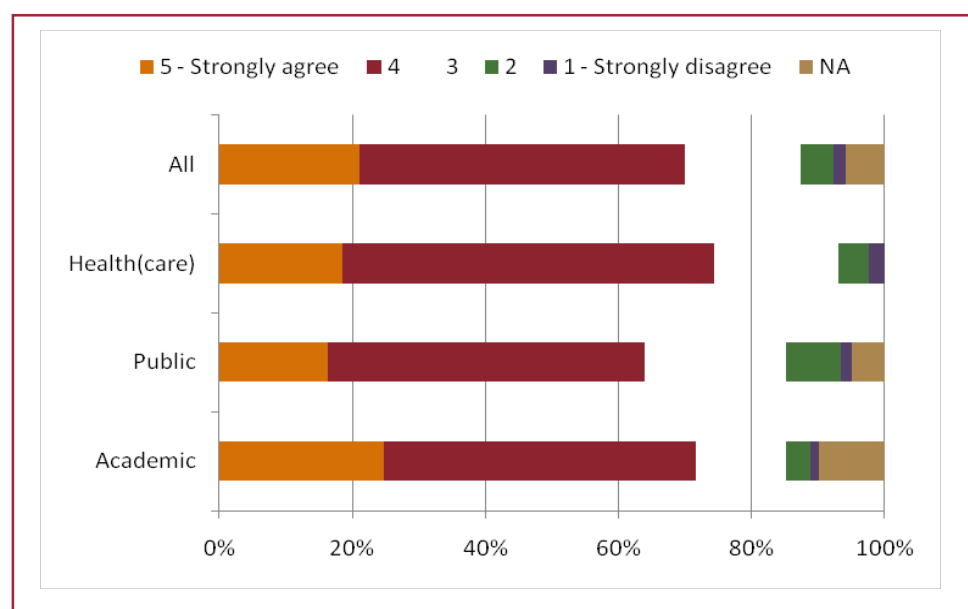

Figure 3 "I would like my local library school to run joint dissemination events to link practitioners and researchers" overseen by a steering group of librarians. So they were strongly engaged in it from the start. These projects integrated sustainability planning and application of lessons learned into practice. It is acknowledged that there is a tension in a collaboratory approach. This is

of research projects that they seek to undertake. For example, through establishing steering committees that include influential stakeholders.

\subsection{Execution of research: the need to involve practitioners for impact}

Our case studies confirm that the engagement of stakeholders in project teams is important in generating impact. Indeed, participation as a data subject is often enough to interest practitioners in the final output of a study. This implies that approaches that bring researchers into close contact with practitioners, such as evidence-based practice and action research, can increase impact. Other involvement activities could include launch events and regular updates, targeted at practitioners, at interim stages of the work. These are especially valuable if they offer opportunities for practitioners to comment on and validate findings.

None of the five case studies consciously presented themselves as "collaboratories" (in the language of Ponti, 2007). However the researchers involved in all the case studies emphasised collaboration with practitioners and stakeholders. For example, Researchers' use of academic libraries was designed with active involvement between the immediate effectiveness that is achieved by strong leadership of an experienced researcher, and participatory decision-making, involving practitioners. While in the long-term the latter increases practitioners' skill-sets, meeting capacity-building and engagement objectives, it can slow progress in a project as the participants go through a learning process, as experienced in the case study with clinical librarians.

Collaborative approaches also address complaints related to the timeliness of the publication of research results, as practitioners are aware of progress throughout the project. This is where the immediacy and engagement inherent in social media, with interim results rapidly disseminated through media such as project blogs, could be important.

Where the motivation for projects explicitly includes capturing and sharing best practice, for example in eValued, researchers are more likely to plan and implement activities to support this, leading to impact. However, we note that the meaning of "best practice" is often not clear, and that it might be better to focus on "good practice".

These points also indicate that strategies for impact should be planned from the outset and integrated into the project as it is executed. Our findings validate the literature that encourages practitioner engagement throughout the project, 
adding specific examples of approaches and activities that support such engagement.

\section{Recommendations: project execution and the involvement of practitioners}

R4. LIS researchers should be encouraged to address practitioner engagement for impact at the project planning stage, for example, by adopting methods, approaches and dissemination strategies that involve practitioners throughout the project.

\subsection{The reporting of findlings: dissemination for impact}

How LIS research is disseminated to, and accessed by, practitioners is vital to any discussion about impact. If practitioners are involved throughout the research, including input into its theme and design, they are more likely to be aware of, and use, its outputs.

Otherwise, our research confirms that face-to-face communication is the most popular way for practitioners to discover relevant research. This is achieved both formally by attending events such as conferences, and through informal discussions. Our study suggests as compared to the current literature, that a greater emphasis should be put on face-to-face communication. This may be due to recent changes in the UK LIS research environment, such as the fragmentation of funding and reporting infrastructures and the emergence of certain sources of research information, such as open access and social media, which do not always benefit from strict bibliographic control.

Other strategies for practitioners to keep up to date with project results include "light touch" monitoring of sources such as newsletters, e-mail lists, or online feeds (with associated complaints of

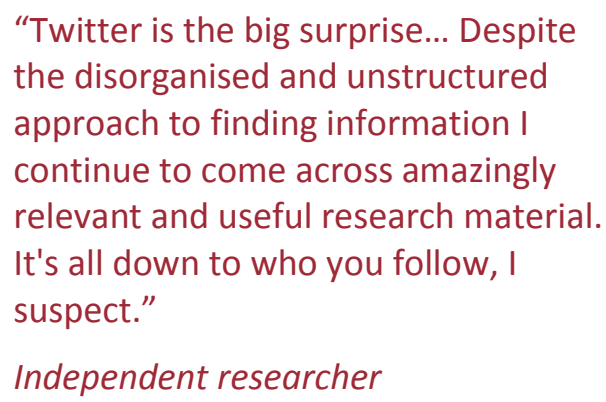

information overload), as well as active searching for relevant material. Practitioners also, and possibly unknowingly, access research findings that have been mediated by others, for example in the form of training materials or blog postings. Similarly, mediated knowledge sharing occurs when colleagues returning from conferences relate findings from the events that they have attended, or newer professionals and students engage in "reverse mentoring".

\begin{tabular}{|l|l|}
\hline Sector & Most significant sources \\
\hline Public & Practitioner journals, mailing lists \\
\hline Academic & $\begin{array}{l}\text { Academic journals, practitioner } \\
\text { journals and mailing lists }\end{array}$ \\
\hline Healthcare & $\begin{array}{l}\text { Academic journals, practitioner } \\
\text { journals and mailing lists/ToC } \\
\text { services }\end{array}$ \\
\hline Table 2 Primary sources for information on research \\
results by major sector
\end{tabular}

As reported in the literature review 3.2.3, practitioners have limited interest in peerreviewed, academic papers. Table 2 illustrates our confirmation of this, particularly for public librarians. JISC mailing lists feature strongly as valuable information sources.

Indeed, along with mailing lists, practitioners show a preference, overall, for less formal dissemination outlets, such as materials produced by CILIP and online channels, including blogs posts and Twitter. Practitioner references to the role of social media in research dissemination represent a new development in the work on the impact of LIS research and merit further exploration.

In cases where practitioners do consult more formal textual reports of research studies, our findings reveal a strong preference among practitioners, particularly managers, for reports that include clear, actionable recommendations for practice.

Participants consulted in this study referred to the need for easily accessible research summaries. Many also regretted that they had only limited access to the research literature. This finding is important because research summaries are available, there are a number of open access repositories of LIS research already in existence, and anyone who is a CILIP member already also 
has access to wide range of research resources (as noted above). This lack of awareness was also reflected in some suggestions for supposedly "new" research projects, which would replicate work that has already been carried out. Many practitioners are unaware that the information they want is already available.

The case studies reveal an important point that links project funding, planning and dissemination. Funders require researchers to set out clear objectives and plans. This means that plans for research dissemination need to be articulated from the outset. The Open to All and eValued projects show how they were able to take advantage of additional funding to develop teaching and community support materials based on their project findings. These had a long-term influence on their impact.

A mixture of dissemination strategies will maximise the likelihood of practitioners finding research results. Scholarly outputs and reports that will be embedded into the academic citation network create a long- term legacy (as found for Open to all). More immediate routes alert "light touch" searchers. These include, for example, LISA searches, newsletters, email lists, Twitter and, specifically, CILIP Update.

eValued and other projects demonstrate the benefits of creating usable artefacts (such as toolkits, training materials) and a sustainable community of practice (CoP) such as "The Network" (Open to all) to support practitioners in the implementation of research findings. However, researchers need to be aware that it can take a lot of work before a CoP is sustainable and efforts need to continue beyond the project itself.
Our findings also indicate the importance of, but also the difficulties in, bringing practitioners together with academic researchers. Noted mainly by academic librarians, these issues are pertinent to academic LIS course content as well as communication channels for research.

Recommendat ions: dissemination for impact

R5. Researchers should be encouraged to develop research dissemination strategies aligned to where and how practitioners access new

information and create (embed) outputs which support the use of research results.

R6. Where appropriate, researchers should be encouraged to include provision for teaching and community support materials in project plans.

R7. Researchers should be encouraged to publish reports with clear lists of recommendations, in accessible language. This is in addition to any academic papers researchers may choose to publish.

R8. Those with responsibility for freely-available open access repositories of LIS research materials should be encouraged to raise awareness of their resources amongst the practitioner communities. Similarly CILIP should publicise membership benefits that include access to a number of research publications. 


\subsection{Organisational factors: Creating a receptive audience}

Our findings confirm that community profile is a factor when it comes to how LIS research is accessed and consumed by different groups of practitioners. For example, those working in academic and healthcare environments are more aware than others of the routes available for accessing research results, and the benefits that practitioners can gain through direct participation in projects.

Two factors are important in how receptive the target audience is. First there are organisational issues related to reward: this was not identified from the literature review, yet came across strongly in our empirical study. As Figure 4 illustrates, practitioners, particularly in the public library sector, reported that engagement with research is simply not rewarded at work. Research is often seen as a distraction from the day-to-day pressures of an environment beset by cost-cutting. A possible implication of this is that practitioners who do not have time to consult research miss opportunities for significant efficiency savings or service enhancements through exploitation of research results. When this is associated with work-place blocking of important social media routes for keeping in touch with other practitioners, many feel excluded from the wider community.

The second main factor, and one which is discussed in the literature review (3.2.4), is the lack of a continuing professional development (CPD) requirement for practitioners to engage with research ${ }^{14}$. We are aware that this forms part of a wider debate and it is clear that, for these issues to be addressed there would need to be joint action by the professional bodies and employers.

A useful model that may be useful to explore further is that self-efficacy. Practitioners need to

\footnotetext{
${ }^{14}$ Although section A2 of CILIP's "Code of Professional Practice for Library and Information Professionals" at http://www.cilip.org.uk/sitecollectiondocuments/PDFs/ policyadvocacy/CodeofProfessionalPracticeforLibraryan dInformationProfessionals.pdf does require professionals to keep abreast of developments in their area of expertise
}

be self-efficacious ${ }^{15}$ in accessing research material. This not only means arming them with the skills and motivations, but also ensuring that positive experiences are reinforced. This is likely to require a mixture of organisational and personal approaches. Research projects and organisations also have a role to play in providing accessible opportunities for face-to-face interaction at all stages in the research life cycle, for example, by creating accessible events based around the research project or sponsoring access to conferences.

\section{Recommendations: training of practitioners for impact}

R9. The LIS research community should explore how practitioners in sectors that are more receptive to research may share good practice with others.

R10. The LIS research community should consider providing training to support practitioners' interest in research.

R11. CILIP should require ongoing CPD to encourage practitioners to engage with research.

\footnotetext{
${ }^{15}$ Self-efficacy is defined as beliefs about one's ability to perform a specific behaviour and produce an effect. Unlike efficacy, which is the power to produce an effect (in essence, competence), self-efficacy is the belief (whether or not accurate) that one has the power to produce that effect.

"People who regard themselves as highly efficacious act, think, and feel differently from those who perceive themselves as inefficacious. They produce their own future, rather than simply foretell it" (Bandura, 1986, p. 231).

Expectations of positive outcomes of behaviour are meaningless if we doubt our capacity to successfully execute the behaviour at all; conversely, previous bad experiences can create a self-reinforcing cycle of expectations of negative outcomes. The analysis focuses on the subjective perspective of the practitioner as well as upon their objective context. In other words, this framework allows exploration of environmental (social, cultural, institutional or educational) and personal factors (experience) behind the decision to (not) engage with research outcomes.
} 


\section{Discussion and conclusions}

\subsection{Overall conclusions}

Through an investigation of the extent to which LIS research projects influence practice, conducted with practitioners and researchers, a number of factors have emerged as important to achieving impact. As well as confirming findings of previous studies related to our main themes, this project has extended our knowledge of the factors that contribute to impact. Our contribution highlights new insights:

- $\quad$ Project leadership, sponsorship and involvement throughout the project help to draw attention to research projects and their outputs, thus increasing the potential for impact.

- $\quad$ Researchers have many options for engaging practitioners in research projects from the outset, and these can be supported by the immediacy of social media. These need to be built into project planning stages.

- Freely-available LIS research resources are not reaching their target population, and some professional body benefits are probably underused due to lack of awareness.

- Organisational attitudes, in an environment of cost-cutting, are not conducive to encouraging practitioner engagement with research.

- Practitioners do not rely on research from a single domain. LIS research is of interest, but so is research from other disciplines.

\subsection{Clarifying the relationship}

\section{between research and practice}

In general, our findings illustrate the close relationship between the four main factors that influence research impact identified in the literature review. These should be seen not as independent categories or parts of a linear process (Figure 5), but as a set of dynamic interactions that come into play, even before a project is formally initiated (Figure 6).

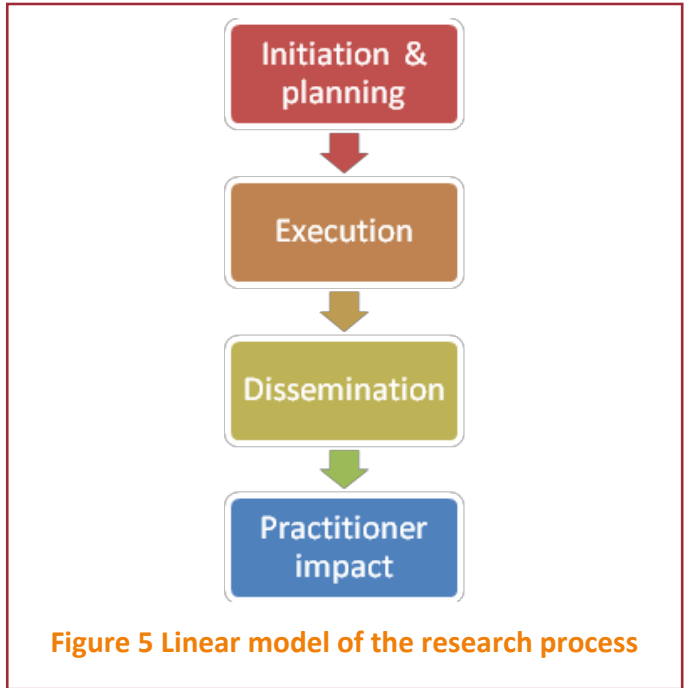

The richer view, in Figure 6 below, emphasises continuous interaction and places the practitioner at the centre.

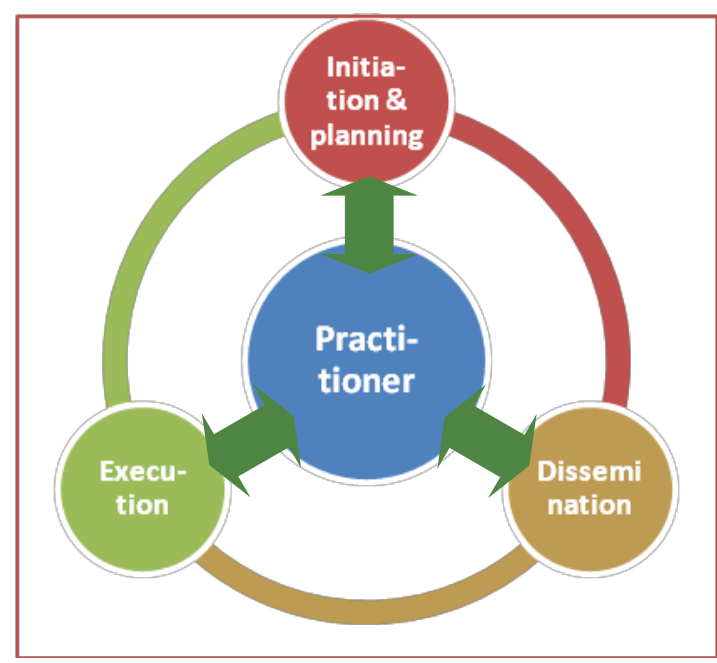

Figure 6 The move to a richer, practitioner centred model for research projects

Our "impactful" case studies involved practitioners in a variety of activities, including scoping and initiating projects, implementation and disseminating results. Such joint work between the researchers and practitioners contributed much to research dissemination and sometimes led to the modification of project plans.

Figure 7 visualises the context of successful impact. It requires an intersection of practitioners, who are supported by their professional bodies and employers in engagement with research, and 
research projects, that produce results seen to be relevant and useful for practitioners and the organisations that employ them.

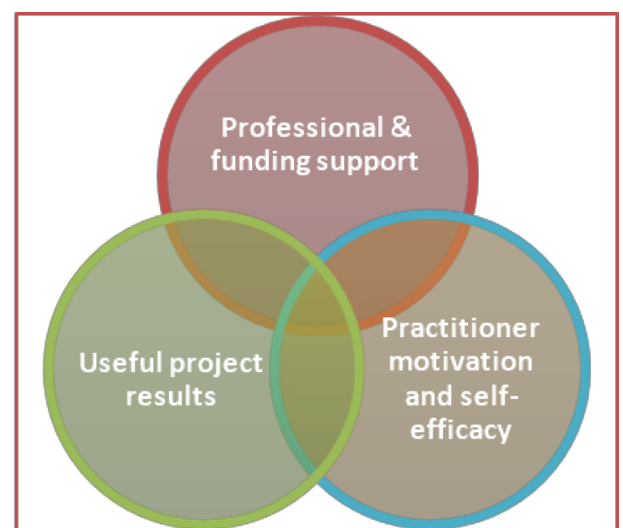

Figure 7 Interacting factors in ensuring research impact

The responsibility does not lie with a single set of actors. When all the factors are in alignment, impact is maximised.

\section{Areas for further work}

The work carried out has highlighted a number of areas where further research would be of benefit. Research questions include:

- What is the role of intermediaries in the translation of research into practice?

- What is the role that social media can play in engaging practitioners in research?

- What is the role of the "library school" in assuring that LIS research has impact?

- How do the LIS communities in other countries encourage research engagement?

- What kind of research from disciplines other than LIS currently contributes to decisionmaking in the practice of library and information services delivery?

- To which other disciplines does LIS research contribute and to what extent to does it have impact beyond its "home" domain?

- What is the impact of major infrastructural changes (e.g. devolution, localism, closure of bodies such as MLA) on the dissemination and take-up of research results?

Practical work that could follow on from this project includes:

- $\quad$ Creation and delivery of training packages to address some of the issues raised by practitioners in the study, for example on effective dissemination.

- A follow-up on the responses to, and implementation of, the recommendations to this report.

- A survey of research information needs amongst the practitioner community.

- $\quad$ Events which bring LIS practitioners and researchers together.

\footnotetext{
"Most research on LIS matters is not difficult to locate. What's missing is a culture of exploiting research to develop and improve services." Experienced consultant
} 


\section{Glossary and acronyms}

\begin{tabular}{|c|c|c|}
\hline Acronym & Explanation & Website \\
\hline AHRC & Arts and Humanities Research Council & www.ahrc.ac.uk \\
\hline BAILER & $\begin{array}{l}\text { British Association for Information and Library Education } \\
\text { and Research }\end{array}$ & www.bailer.org.uk \\
\hline CILIP & $\begin{array}{l}\text { Chartered Institute of Library and Information } \\
\text { Professionals. Professional body formed following the } \\
\text { unification of the Institute of Information Scientists (IIS) } \\
\text { and the Library Association (LA). }\end{array}$ & \begin{tabular}{|l|} 
www.cilip.org.uk \\
\end{tabular} \\
\hline CoP & Community of practice & \\
\hline CURL & Consortium of University Research Libraries & www.rluk.ac.uk \\
\hline EBLIP & $\begin{array}{l}\text { Evidence Based Library and Information Practitioners: } \\
\text { journal and associated conferences }\end{array}$ & www.eblip6.salford.ac.uk \\
\hline EIS & Electronic information services & \\
\hline HEFCE & Higher Education Funding Council for England & www.hefce.ac.uk \\
\hline HEI & Higher education institution & \\
\hline HLG & (CILIP) Health Libraries Group & $*$ \\
\hline ICT & Information and Communications Technology & \\
\hline INASP & $\begin{array}{l}\text { International Network for the Availability of Scientific } \\
\text { Publications }\end{array}$ & http://www.inasp.info/ \\
\hline JISC & $\begin{array}{l}\text { Provide leadership and infrastructure in the use of ICT in } \\
\text { support of learning, teaching, research and } \\
\text { administration (formally an acronyn for Joint Information } \\
\text { Systems Committee). }\end{array}$ & www.jisc.ac.uk \\
\hline LIC & Libraries and Information Council & \\
\hline LIRG & (CILIP) Library and Information Research Group & * \\
\hline LISA & Library and Information Science Abstracts service. & \\
\hline LIS & $\begin{array}{l}\text { Library and Information Science, the research field. } \\
\text { (References to library and information service(s) are } \\
\text { always spelled out in full). }\end{array}$ & \\
\hline MLA & $\begin{array}{l}\text { Museum \& Library Association. (Duties taken on by the } \\
\text { Arts Council from October 2011.) }\end{array}$ & www.mla.gov.uk \\
\hline OCLC & $\begin{array}{l}\text { American/British not for profit library computer service } \\
\text { and research organisation. }\end{array}$ & www.oclc.org \\
\hline Re:source & $\begin{array}{l}\text { Successor to LIC; superseded by the MLA which took } \\
\text { over responsiblity for LIS research funding }\end{array}$ & \\
\hline REF & Research Excellence Framework & www.ref.ac.uk \\
\hline RLUK & Research Libraries UK & www.rluk.ac.uk \\
\hline RIN & Research information network & www.rin.ac.uk \\
\hline SCONUL & Society of College, National and University Libraries & www.sconul.ac.uk \\
\hline SLAINTE & Information and libraries Scotland & www.slainte.org.uk \\
\hline SLIC & $\begin{array}{l}\text { Chartered Institutue of Library and Information } \\
\text { Professionals in Scotland }\end{array}$ & \begin{tabular}{|l|} 
www.slainte.org.uk/slic/ \\
slicindex.htm \\
\end{tabular} \\
\hline SLG & (CILIP) School Library Group & $*$ \\
\hline UC\&R & $\begin{array}{l}\text { (CILIP) University, College and Research group. Brings } \\
\text { togerther academic librarians from across the UK. }\end{array}$ & * \\
\hline UNISON & Public sector trade union & www.unison.org.uk \\
\hline
\end{tabular}

*Information on CILIP special interest groups can be accessed via www.cilip.org.uk/get-involved/specialinterest-groups 


\section{References}

Ahlgren, P., \& Järvelin, K. (2010). Measuring impact of twelve information scientists using the $\mathrm{DCl}$ index. Journal of the American Society for Information Science and Technology, 61(7), 1424-1439. doi: 10.1002/asi.21333

Åström, F. (2008). Formalizing a discipline: The institutionalization of library and information science research in the Nordic countries. Journal of Documentation, 64(5), 721-737.

Bandura, A .(1986). Social foundations of thought and action: a social cognitive theory. Englewood Cliffs, NJ: Prentice Hall

Bawden, D. (2008). Smoother pebbles and the shoulders of giants: the developing foundations of information science. Journal of Information Science, 34(4), 415-426. doi: 10.1177/0165551508089717

Berg, S., Hoffmann, K., \& Dawson, D. (2009). Integrating research into LIS field experiences in academic libraries. The Journal of Academic Librarianship, 35(6), 591-598. doi: 10.1016/j.acalib.2009.08.007

Booth, A. (2003). Bridging the research-practice gap? The role of evidence based librarianship. New Review of Information and Library Research, 9(1), 323.

Bowler, L., \& Large, A. (2008). Design-based research for LIS. Library \& Information Science Research, 30(1) 39-46. doi: 10.1016/j.lisr.2007.06.007

Brettle, A., Maden-Jenkins, M., Anderson, L., McNally, R., Pratchett, T., Tancock, J. (2011). Evaluating clinical librarian services: a systematic review. Health Information \& Libraries Journal, 28(1), 3-22. doi: 10.1111/j.1471-1842.2010.00925.x

Craghill, D., \& Wilson, T. D. (1987). The impact of information research. London: British Library.

Cronin, B., \& Meho, L. (2007). Timelines of creativity: a study of intellectual innovators in information science. Journal of the American Society for Information Science and Technology, 58(13), 19481959.

Drummond, R., \& Wartho, R. (2009). RIMS: The Research Impact Measurement Service at the University of New South Wales. [report]. Australian Academic \& Research Libraries, 40(2), 12

Eve, J., \& Schenk, N. (2006a). Interactions between library, archive and information management researchers and library, archive and management professionals: Final Report. Brighton: University of Brighton.

Eve, J., \& Schenk, N. (2006b). Research and practice: findings from the Interactions project. Library \& Information Research, 30(96), 36-46.

Feather, J. (2009). LIS research in the United Kingdom: Reflections and prospects. Journal of Librarianship and Information Science, 41(3), 173-181. doi: 10.1177/0961000609337096

Fried, S., Kochanowicz, M., \& Chiranov, M. (2010). Planning for impact, assessing for sustainability. Performance Measurement and Metrics, 11(1), 5674.
Haddow, G. (2010). Communicating research to practice: The role of professional association publications. Library \& Information Research, 34(108), 33-44.

Haddow, G., \& Klobas, J. E. (2004). Communication of research to practice in library and information science: Closing the gap. Library \& Information Science Research, 26(1), 29-43.

Higher Education Funding Council for England. (2011). Assessment framework and guidance for submissions. Bristol: HEFCE.

Klobas, J. E., \& Clyde, L. A. (2010). Beliefs, attitudes and perceptions about research and practice in a professional field. Library \& Information Science Research, 32(4), 237-245. doi: 10.1016/j.lisr.2010.07.004

Lockyer, S., \& Conyers, L. A. (2007). Value and Impact Measurement Programme.

Markless, S., \& Streatfield, D. (2005). Facilitating the impact implementation programme. Library and information research, 29(91), 8-13.

Martyn, J., \& Cronin, B. (1983). Assessing the impact and benefits of information and library research. Journal of Documentation, 39(3), 171-191. doi: 10.1108/eb026747

McKnight, S., \& Booth, A. (2010). Identifying customer expectations is key to evidence based service delivery. Evidence based library and information practice, 5(1), 26

McMenemy, D. (2010). Fostering a research culture in UK library practice: barriers and solutions. Library Review, 59(5), 321-324.

McNicol, S. (2004). The eVALUEd toolkit: a framework for the qualitative evaluation of electronic information services. Vine, 34(4), 172-175.

McNicol, S. (2005). The importance of evaluation and evidence-based skills to improving service delivery. Library and information research, 29(93), 26-34.

Melo, L. B., \& Pires, C. (2008). Performance evaluation of academic libraries: implementation model. Paper presented at the 17th Helenic Conference of Academic Libraries, Universityt of Ioannina.

Oppenheim, C. (2007). Using the h-index to rank influential British researchers in information science and librarianship. Journal of the American Society for Information Science and Technology, 58(2), 297 301.

Partridge, H., Thorpe, C., \& Edwards, S. (2007). The practitioner's experience and conception of evidence based library and information practice: an exploratory analysis. Paper presented at the 4th International Evidence Based Library and Information Practice Conference, Chapel HillDurham, NC, USA. http://eprints.qut.edu.au/9946/

Pfeffer, J., \& Sutton, R. I. (2006). Evidence-based management. Harvard Business Review(January), 63-74.

Poll, R., \& Payne, P. (2006). Impact measures for libraries and information services. Library Hi Tech, 24(4), 547-562. 
Ponti, M. (2007). A LIS collaboratory to bridge the research-practice gap. Library Management, 29(4/5), 265-277.

Rooney-Browne, C. (2011). Methods for demonstrating the value of public libraries in the UK: a literature review. Library and Information Research, 35(109), 3-37.

Schlogl, C., \& Stock, W. G. (2008). Practitioners and academics as authors and readers: the case of LIS journals. [Article]. Journal of Documentation, 64(5), 643-666. doi: 10.1108/00220410810899691

Shenton, A. K. (2008). The frustrations of writing research articles for publication and what to do about them. Library \& Information Research, 32(101), 15-22.

Smith, K., \& Harvey, R. (2006). Is there a role for professional associations in fostering research? Singapore: Nanyang Technological Univ.

Sonnenwald, D., Lassi, M., Olson, N., Ponti, M., \& Axelsson, A. (2009). Exploring new ways of working using virtual research environments in library and information science. Library Hi Tech, 27(2), 191-204. Special Libraries Association. (2001, Juen 2001). Putting OUR Knowledge to Work: A New SLA Research Statement June 2001 - The Role of Research in Special Librarianship Retrieved 31 July 2011, from http://www.sla.org/content/resources/research/rsr chstatement.cfm

Town, S. (2006). Value and Impact Measurement: A UK Perspective and Progress Report on a National Programme (VAMP). Paper presented at the
Proceedings of the 2006 Library Assessment Conference.

http://vamp.diglib.shrivenham.cranfield.ac.uk/proje ct/Virginia\%20paper.pdf

Turner, K. J. (2002). The use of applied library and information studies (LIS) research in New Zealand libraries. Library Review, 51(5), 230-240.

Walter, I., Nutley, S., \& Davies, H. (2003). Research impact: A cross sector review. Literature review ESRC.

Wavell, C., Baxter, G., Johnson, I., \& Williams, D. (2002). Impact evaluation of museums, archives and libraries: available evidence project. [evaluation report]. Resource-The Council for Museums, Archives, and Libraries, London.

Weightman, A., Urquhart, C., Spink, S., \& Thomas, R. (2009). The value and impact of information provided through library services for patient care: developing guidance for best practice. Health Information \& Libraries Journal, 26(1), 63-71. doi: 10.1111/j.1471-1842.2008.00782.x

Weller, T., \& Haider, J. (2007). Where do we go from here? An opinion on the future of LIS as an academic discipline in the UK. Aslib Proceedings, 59(4/5), 475-482.

Zhao, D. (2010). Characteristics and impact of grantfunded research: a case study of the library and information science field. Scientometrics, 84(2), 293-306. doi: 10.1007/s11192-010-0191-y 


\section{Appendices}

Focus group details

\begin{tabular}{|l|l|l|l|}
\hline Date & 2 June 2011 & 20 June 2011 & 28 June 2011 \\
\hline Event & Slainte meeting, Perth & UC\&R meeting, London & EBLIP6 conference, Salford \\
\hline Host body & Slainte & Regents College & University of Salford \\
\hline Focus group members & Senior Public Librarians & Research/academic librarians & Healthcare librarians \\
\hline Focus group leader & Ella Taylor-Smith & Peter Cruickshank & Ella Taylor-Smith \\
\hline $\begin{array}{l}\text { Other RiLIES team } \\
\text { members attending }\end{array}$ & Hazel Hall, Jenny Gebel & Jenny Gebel & Hazel Hall, Jenny Gebel \\
\hline Group size & 10 & 8 & 12 \\
\hline
\end{tabular}

\section{Information sources mentioned in the validation survey}

This is a selection of the valued information sources mentioned by practitioners in the final survey. All were ranked first by at least one respondent:

CILIP sources: CILIP journals (in general), CILIP news, CILIP Update \& Gazette, Health Information \& Libraries Journal, Health Libraries Group newsletter, Library and Information Research, LIRG bulletin, Public Library Journal, Slainte web site

JISC sources: JISC mailing lists in general, and specific lists JISC-REPOSITORIES, LIS-E-RESOURCES, LIS-LINK, LISLIRG, LIS-MEDICAL, LIS-PROFESSION, LIS-PUB-LIBS, LIS-SERIALS, LIS-WALES, RESEARCH-DATA-MAN

Journals: ALA and ALISS publications, transport Journals (e.g. Local Transport Today, Surveyor, Planning), British Medical Journal, Evidence Based Library and Information Practice, Information Research, Issues in Science \& Technology Librarianship, Journal of Mixed Methods Research, Library Journal, Library Research Journal, New Scientist, SCONUL Focus

Newletters: ARL Weekly Update, info4local, OCLC Newsletter, RDFunding

Databases and secondary sources: EMERALD journals database, Google Scholar, LISA, NHS Evidence Healthcare databases, Medscape

Organisational web sites and blogs: Clinical Librarians' Feed, Evidence Based Library \& Information Practice Blog, FreePint, Informed Librarian Online, LIS New Professionals Network, LIS Research Coalition, MLA, National Literacy Trust, The Network, NHS Institute, Repositories Support Project, RIN, School Librarians' Network, Voices for the Library

Bloggers: David Bawden, Phil Bradley, Peter Godwin, Buffy Hamilton, Brian Kelly, Dave Pattern, Jane Secker, Sheila Webber

Twitter feeds: @aarontay, @alanfricker, @andrewspong, @bibliothekarin, @ISKOUK, @LIS_RiLIES, @LISResearch, @PhilBradley, @readingagency, @ukcorr, @vonburkhardt 